\title{
Homofobia e Sexualidade em Adolescentes: Trajetórias Sexuais, Riscos e Vulnerabilidades
}

Homophobia And Sexuality In Adolescents: Sexual Trajectories, Risks And Vulnerabilities

Homofobia Y Sexualidade En Adolescentes: Trayectorias Sexuales, Riesgos Y Vulnerabilidades
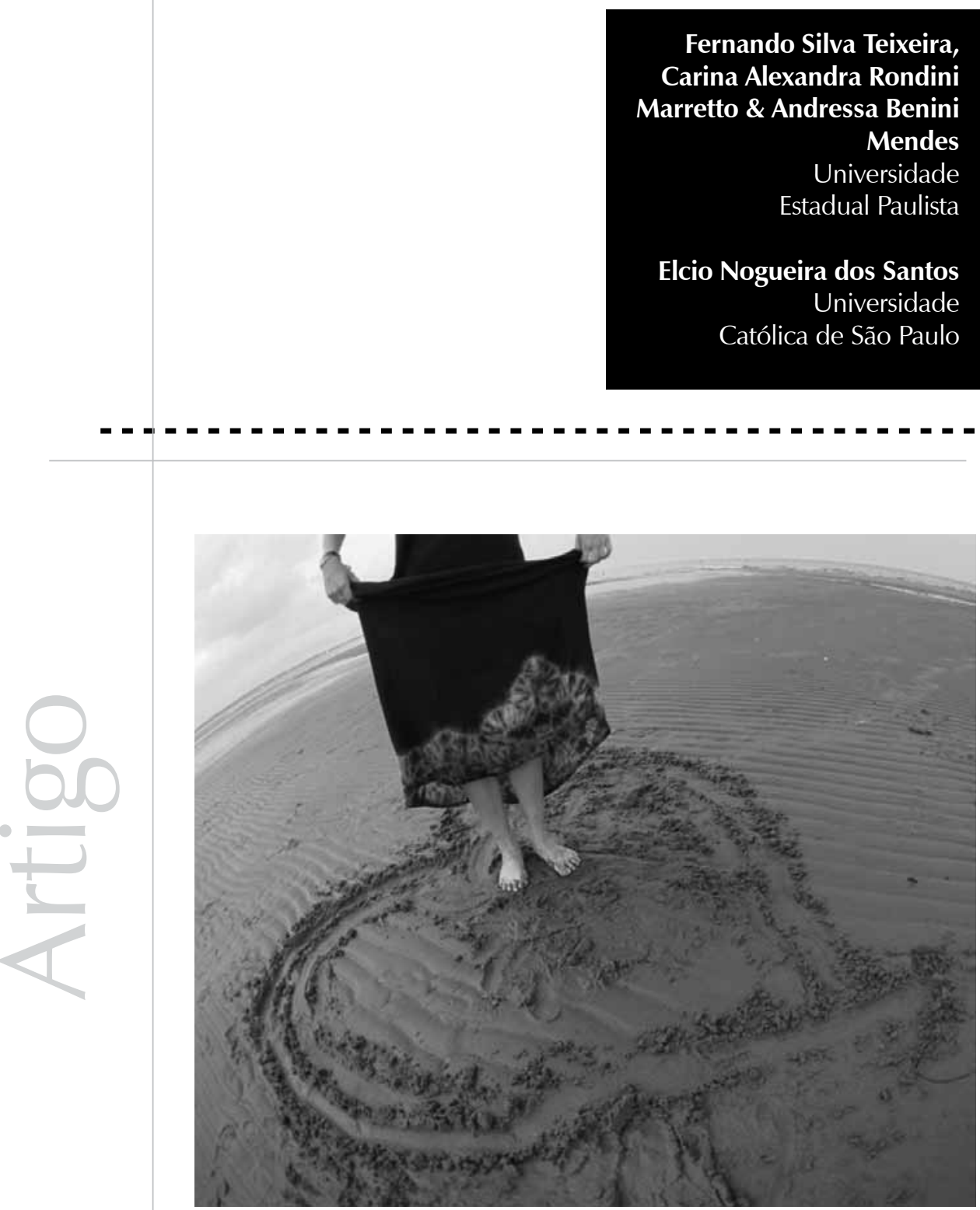
Projeto de pesquisa aprovado em edital lançado em 2007 dentro do Acordo de Cooperação PN-DST/HIV-AIDS - SVS/Ministério da Saúde/Bird/Unodc (projeto ad/bra/03/ h34 - acordo de empréstimo Bird no 4713-BR). O projeto foi desenvolvido em regime de parceria pelas seguintes instituições: Ong NEPS

(Núcleo de Estudos e Pesquisas sobre as Sexualidades), na qualidade de mantenedora, pelo Grupo de Estudos e Pesquisas sobre as Sexualidades (GEPS) vinculado ao Dep. de Psic. Clínica da Unesp de Assis e em parceria com pesquisadores de outras instituições (UNESP-Presidente Prudente via

NUDISE [Núcleo de Diversidade na Educação], UERJ, UnB, UFRGS, PUC/SP, C.O.R.S.A. e UNICAMP), respectivamente na qualidade de executoras/es e colaboradoras/es.

Resumo: Esta pesquisa é um estudo transversal realizado junto a 2282 estudantes de ambos os sexos que cursavam as três séries do ensino médio em três cidades do interior do oeste paulista. $\mathrm{O}$ instrumento de coleta de dados empregado foi um questionário autoaplicável com 131 questões. Neste artigo, abordamos as trajetórias sexuais de adolescentes de ambos os sexos que mantêm práticas sexuais homoeróticas ou não. Discutimos as relações desses adolescentes com seus familiares e grupos de pares e a questão de sair do armário como ferramenta política. Tendo como base as concepções de Sedgwick, analisamos os momentos em que sair do armário pode ser uma entre tantas maneiras de manifestação das diferentes sexualidades em relação à heteronormatividade. Apoiando-nos nas colocações de teóricos pós-estruturalistas, abordamos também as construções teóricas e as produções discursivas sobre a adolescência, apontando novas manifestações da juventude na contemporaneidade. Por fim, percebemos a existência de amplos fatores que afetam as decisões de jovens não heterossexuais quanto a sair (ou não) do armário para além da homofobia: eventos pessoais, histórias de vida e mesmo a revelação de sua sexualidade aos pais e/ou a outras pessoas.

Palavras-chave: Atitudes sexuais. Atitudes frente à identidade sexual. Discriminação sexual. Adolescência. Homofobia.

Abstract: This is a descriptive analytical cross-sectional study conducted with 2282 male and female students who attended high school in three cities of the western interior of São Paulo, Brazil. Data collection was done by a self-reported questionnaire with 131 questions. This paper discusses the sexual trajectories of these adolescents who enrolled in homoerotic sexual practices or not. These adolescents' relationships with their families, peer groups and the subject of "coming out" are discussed as political tools. Based on Sedgwick's concepts we analyze the moments when "coming out" can be one in many other ways of manifestation of different sexualities in relation to heteronormativity. Relying on post-structuralism theories, we also discuss theoretical constructions and discourses about adolescence, pointing at new manifestations of juvenile in contemporaneity. Finally, we realize the existence of many factors that affect the decisions of non-heterosexual youths in relation to "coming out of the closet" beyond homophobia: personal events, life stories and even the revelation of their sexuality to their parents and/or to others.

Keywords: Sexual acttitudes. Sex role attitudes. Sex discrimination. Adolescence. Homophobia.

Resumen: Se trata de estudio transversal realizado junto a 2.282 estudiantes de ambos sexos cursando los tres cursos de la Enseñanza Media en tres ciudades del interior del Oeste Paulista. El instrumento de colecta de datos empleado fue un cuestionario auto-aplicable con 131 cuestiones. En este artículo abordamos las trayectorias sexuales de adolescentes de ambos los sexos que mantienen prácticas sexuales homoeróticas o no. Discutimos las relaciones de esos adolescentes con sus familiares y grupos de pares y la cuestión de "salir del armario" como herramienta política. Teniendo como base las concepciones de Sedgwick, analizamos los momentos en que 'salir del armario' puede ser una entre tantas maneras de manifestación de las diferentes sexualidades en relación a la heteronormatividad. Apoyándonos en las propuestas de teóricos posestructuralistas abordamos también las construcciones teóricas y las producciones discursivas sobre la adolescencia, apuntando hacia nuevas manifestaciones de la juventud en la contemporaneidad. Por fin, percibimos la existencia de amplios factores que afectan a las decisiones de jóvenes no heterosexuales en lo referente a 'salir (o no) del armario' más allá de la homofobia: eventos personales, historias de vida e incluso la revelación de su sexualidad a sus padres y/o a otras personas.

Palabras clave: Actitudes sexuales. Actitudes frente a la indentidad sexual. Adolescencia. Homofobia.

Os historiadores da história nova, especialmente Ariès (1978), mostraram-nos que a infância e a adolescência, como nós as entendemos hoje, é uma construção social e histórica, tendo sido produzida a partir do final da Idade Média. Logo, não é vista da mesma maneira em todas as épocas históricas e culturais. É bem verdade que as transformações biológicas e hormonais são inerentes a todos os seres humanos, mas as maneiras como as diferentes culturas e épocas históricas as percebem e interpretam divergem muito ao longo do tempo.

Na sociedade ocidental, a concepção de adolescência vem sofrendo transformações em função das mudanças históricas. Até o início do século XX, um jovem de catorze anos, dada sua inserção social, estava apto ao mercado de trabalho, e, aos dezesseis, já poderia constituir família. $\mathrm{O}$ que mudou? $\mathrm{O}$ corpo humano? O comportamento sexual 
Assim, podemos afirmar que a adolescência, como outras categorias de análise, é construída social e historicamente, e é articulada e atravessada por marcadores sociais de diferença tais como classe, raça/etnia, sexualidade e gênero, os quais, interseccionados, produzem diversidades de trajetórias adolescentes (Oliveira, 2007). e seu desenvolvimento? Não. Foram os discursos (acadêmicos, científicos, religiosos) que se ocuparam em explicar a adolescência. Tais discursos nascem das transformações que a Revolução Industrial trouxe para esse período da vida. Atualmente, prolonga-se a adolescência. Oficialmente, pela OMS (WHO, 1986), a adolescência é concebida como um período que tem início aos 10 e vai até os 19 anos de idade. Entretanto, na perspectiva da pediatria contemporânea, uma criança de 10 anos é pré-púbere, isto é, na maioria dos casos, seus órgãos genitais internos e externos ainda não estão completamente maturados do ponto de vista de suas funções reprodutivas, mas isso, em algumas culturas pré-industriais, não as impede de serem inseridas em práticas sexuais com múltiplos parceiros, sejam da mesma idade, seja com crianças mais velhas, seja com adultos, até mesmo como forma de contracepção (Currier, 1985). Tal lógica, em nossa sociedade sexualmente repressiva, é encarada como violência segundo o Estatuto da Criança e do Adolescente - ECA (1990). Assim, podemos afirmar que a adolescência, como outras categorias de análise, é construída social e historicamente, e é articulada e atravessada por marcadores sociais de diferença tais como classe, raça/ etnia, sexualidade e gênero, os quais, interseccionados, produzem diversidades de trajetórias adolescentes (Oliveira, 2007). Desse modo, é impossível falarmos de adolescência, senão de adolescências.

\section{Adolescências e homossexualidades}

As questões sobre as relações entre adolescência, desenvolvimento identitário e orientação sexual ainda estão em aberto. Há diversos posicionamentos teóricos e discursivos que irão responder de modo diverso a questões comuns a todos os que trabalham com adolescentes e com identidades e orientações sexuais, tais como: existiriam diferenças entre o desenvolvimento de adolescentes heterossexuais e os não heterossexuais? Se sim, em que elas consistem? Quando e como elas aparecem e por quanto tempo? Por que elas aparecem? Elas podem ser eliminadas? Deveríamos nos preocupar em estimulá-las ou mesmo reconhecê-las? Se sim, por quê? E as questões de gênero? Que importância têm nessa construção? De que modo se define a homossexualidade? Ela existiria desde sempre, ou seja, já na infância?

De um lado, encontraremos teorias que irão advogar em favor da ausência de diferenças entre hetero e homossexuais em termos de desenvolvimento, alegando que as mesmas serão causadas pelo preconceito social em torno da homossexualidade, aqui chamada de homofobia (Borrillo, 2001; Eribon, 2008). Por outro lado, há autores, como Bailley e Pillard (1991), Hamer, Hu, Manguson e Pattattucci (1993) e LeVay (1991), que assumem um discurso biologizante em torno da questão, defendendo a tese de que diferenças hormonais ainda em estado fetal seriam as causadoras dessas diferenças em relação ao grupo de hetero e homossexuais. Em direção oposta, encontramos interpretações culturalistas como as de Seidman (2003), que concebem a questão dessas diferenças como resultado de conflitos erigidos a partir do momento em que as pessoas não compatibilizam suas performances de gênero (Butler, 2003) e/ou desejo de acordo com aquilo que é social e arbitrariamente considerado adequado para cada sexo. Do mesmo modo, e também aqui, estudos já antigos apontavam diferenças entre adolescentes de mesma categoria analítica (hetero ou homo, por exemplo) que eram atravessadas pelas questões raciais (Broderick, 1966 citado em Martinson, 1984).

Por fim, temos também autores (Ryan \& Futterman, 1998; Castañeda, 2007) que, partindo de observações clínicas, de resultados de pesquisa e de experiência pessoal com juventude não heterossexual, acreditam que 
1 Versão nossa do original em inglês: O desenvolvimento é determinado em grande parte pelo que previamente aconteceu na vida de um indivíduo, incluindo aí suas predisposições genéticas, fatores ambientais e interações. E

mais, como em

qualquer história de vida, acontecem momentos decisivos ou incidentes críticos que desencadeiam processos de

desenvolvimento particulares ou transições em movimento.

Um destes, para muitos jovens de minorias sexuais, é a descoberta, pelos pais, de sua sexualidade. Uma ampla variedade de considerações existe quando, como e porque isso ocorre, de modo que reforçam uma perspectiva de diversidade.

2 Versão nossa do original em inglês: "orientação sexual não dita necessariamente a essência do que significa ser humano, mas ela de fato serve para demarcar alguns aspectos do desenvolvimento".

3 Versão nossa do original em espanhol: "Os juízos antes expostos sobre a literatura da sexualidade infantil não podem ser inteiramente mantidos após a publicação da grande obra de Stanley Hall" (Adolescência, sua psicologia e suas relações com não haja diferenças entre os jovens homo ou heterossexuais. Savin-Williams (2001, 2005) é partidário do posicionamento de que, para ambos (hetero ou homossexuais), a adolescência não é um período da vida que se possa homogeneizar. Trata-se antes de pensar em trajetórias de desenvolvimento e não em ciclos e/ou estágios específicos independentemente de suas origens. Em suas palavras:

Development is determined to a large degree by what has previously transpired in an individual's life, including genetic predispositions, environmental events, and their interactions. Yet, within any life history, turning points or critical incidents occur that set particular developmental processes or transitions in motion. One of these for many sexual-minority youths is their parent's discovery of the youth's sexuality. Wide variations exist concerning when, how, and why this occurs, thus supporting a perspective of diversity (Savin-Williams, 2001, p. 9) ${ }^{1}$

Concordando com esse autor, acreditamos que não haja diferenças inatas no desenvolvimento psicossocial de jovens independentemente de suas orientações sexuais. Entretanto, o que nos interessa é perceber que, por causa da homofobia como processo e prática regulatória das identidades de gênero, desejo e orientação sexual visando à manutenção do heterocentrismo (pressuposição de que todos os homens ou todas as mulheres são, por princípio, heterossexuais) e do heterossexismo (pressuposição de que a heterossexualidade é a única forma válida, normal, legítima, de expressão da sexualidade), os jovens que não se enquadram na heteronormatividade (pressuposição de uma diferença natural entre o masculino e o feminino tomada a partir de seus sexos biológicos) necessariamente irão experimentar trajetórias diferenciadas em seu desenvolvimento em comparação com os jovens heterossexuais. Como nos dirá Savin-Williams: "Sexual orientation does not necessarily dictate the essence of what it means to be human, but it does serve to demarcate some aspects of development ${ }^{2 \prime}$ (1990, p.11).

\section{Teorias de desenvolvimento e construção da identidade}

Em sua pesquisa sobre a emergência do conceito de adolescência, Santos (1996) nos diz que o médico Stanley Hall (1846/1924) é reconhecido atualmente como o "pai" do movimento do estudo da criança nos Estados Unidos. Sua obra, especialmente Adolescence (1904), é um exemplo cristalino do conceito biológico de Darwin trasladado para a Psicologia. O autor nos conta que Hall, em intensas trocas de correspondências com Freud, postula os primeiros componentes do que seria o discurso atual sobre a adolescência. Hall se baseia em alguns escritos de Freud, especialmente em Tres ensayos para una teoria sexual (1905/1981). Sobre a obra de Stanley Hall, Freud (1905/1981, p.1195), em nota de rodapé, afirma: "Los juicios antes expuestos sobre la literatura de la sexualidad infantil no pueden ser ya enteramente mantenidos después de la publicación de la gran obra de Stanley Hall"3.

Butler (2003, 2005) critica contundentemente essa posição psicanalítica e biologizante afirmando que as mesmas nascem de supostas predisposições existentes nos sujeitos, ou seja, anteriores à linguagem. Tais predisposições, isto é, essências, levariam os sujeitos a uma heterossexualidade normal. Esse discurso essencialista, ainda que não seja intencional por parte dos autores, funciona como regulador das relações sociais entre os sexos e implicam a manutenção e a (re) produção discursiva da heterossexualidade compulsória, excluindo assim outros modos, sentimentos e desejos que não sejam os heterossexualizados.

Segundo Savin-Williams (2005), em uma perspectiva histórica, veremos que os estudos sobre o desenvolvimento de adolescentes 
homossexuais empreendidos, por exemplo, na América e na Europa desde os anos 70 até o presente passaram por inúmeras transformações influenciadas tanto pelos discursos naturalistas e naturalizados da Biologia e da Filosofia bem como pelos discursos empreendidos pelas feministas e psicanalistas francesas (Simone de Beauvoir [1949] 1980), Elizabeth Badinter [1985], Julia Kristeva [1982]), pelas americanas Joan Scott (1989), Gayle Rubin (1975, 1984), Judith Buttler $(1987,2003)$ e pelos estudos culturais (Jefrey Weeks [1985], Stuart Hall [1981] e Steven Seidman [2003]). No Brasil, ainda não encontramos teóricos desenvolvimentistas que estejam preocupados em interseccionar esses marcadores sociais com os modelos de desenvolvimento da Psicologia.

Infelizmente, pouco se tem avançado em termos de teorias sobre o desenvolvimento de identidades homossexuais (ou não) na Psicologia. Em geral, elas se baseiam em achados (nem sempre seguros) das ciências biológicas (vinculando o sujeito do desejo ao seu desenvolvimento biológico) ou então em referentes psíquicos fixos, como, por exemplo, o complexo de Édipo para a psicanálise, segundo a qual a homossexualidade é ainda vista como perversão (Costa, 1992, 1995). Isso atrela também o desenvolvimento psíquico do sujeito, ou seja, as emoções, os desejos e as angústias ao crivo da passagem pelo Édipo como determinante das escolhas objetais inconscientes do desejo (sexual ou não). Trata-se, porém, de um crivo conceitual que não dá conta da

a psicologia, antropologia, sociologia, sexo, crime, religião e educação) (Adolescence, its psychology and its relations to psychology, antropology, sociology, sex, crime, religion and education (New York, 1904). multifatorialidade e da multiconfiguração das famílias contemporâneas, cujos arranjos de filiação, pertencimento, conjugalidade e parentalidade são diversos daqueles da família nuclear burguesa do século XIX que inspirou a produção desse modelo teórico.

Em nosso ponto de vista, a identidade é uma produção discursiva que é atravessada por diferentes marcadores sociais, tais como raça/etnia, gênero, classe, escolaridade e sexualidade. Uma identidade não é apenas marca para o sujeito, é também para toda a sociedade, ou seja, assumir uma identidade tem um caráter não só pessoal mas também político. Definir-se homossexual também é uma forma de se integrar a um estilo de vida e assim fazer parte de um grupo, é entrar em um meio até então desconhecido e encontrar (ou fugir de) seus iguais.

Considerando o fato de que vivemos em uma sociedade heterossexista e heteronormativa, jovens que se autodeclaram não heterossexuais vivem o dilema de assumirem-se para si mesmos e para os outros e pagarem o preço do ostracismo e da vitimização. O preço é alto, pois os índices de violência (Facchini, França, \& Venturi, 2007; Carrara, Ramos, Simões, \& Facchini, 2006) e a sordidez com que crimes contra pessoas homossexuais são praticados (Mott, 2000), bem como a invisibilidade das sexualidades não heterossexuais nas leis (Rios, 2002), nas regras e nas normas escolares, enfim, no cotidiano em geral, empurram o jovem para o isolamento.

Nesse sentido, entrar em um grupo homossexual é também (des)construir uma identidade, aprender novos códigos e novas formas de se olhar e de se posicionar diante do mundo. Para Hall, "identidade, apesar de ser um conceito sob rasura, ainda é importante para se pensar os sujeitos e suas multiplicidades" (2000, p. 103). Desse modo, a identidade é relacional, socialmente construída e, importante lembrar, desconstruída. É a fusão de valores culturais, desejos, práticas, sentimentos e, principalmente, a tomada de consciência disso tudo que irá formar uma identidade sexual, (Castañeda, 2007), seja ela hetero, homo ou bissexual. Todavia, vale lembrar que essas constituem possibilidades diferentes na igualdade, pois, mesmo diferentes, todas são formas de se viver a sexualidade. 
De todo modo, neste trabalho, tentaremos compreender como, a partir dos estudos pósestruturalistas sobre gênero e sexualidade, poderemos perceber os sentidos e as variações do sair-do-armário em adolescentes e as suas articulações com marcadores sociais como raça, gênero e classe social.

\section{Construção da identidade homossexual e a negociação do sair do armário}

Assim, sair do armário é entendido aqui como um processo de reconhecimento dos sentimentos e afetos homoeróticos ou de pertencerem a outro gênero diferente do culturalmente esperado para o seu sexo biológico, para si mesmo e para os outros. Partindo desse pressuposto, iremos investigar fatores que são levados em conta por jovens não heterossexuais no momento em que consideram a possibilidade de sair do armário, de modo que essa questão se torna central em suas vidas.

Em um artigo seminal, Sedgwick discute o que chama de "epistemologia do armário". Segundo a autora, após o movimento de Stonewell, a autorrevelação de uma identidade homossexual prometia uma grande libertação da opressão vivida por pessoas homossexuais. Entretanto, como afirma a autora,

Cada encontro com uma nova turma de estudantes, para não falar de um novo chefe, assistente social, gerente de banco, senhorio, médico, constrói novos armários cujas leis características de ótica e física exigem, pelo menos da parte das pessoas gays, novos levantamentos, novos cálculos, novos esquemas e demandas de sigilo ou exposição. (...) O armário gay não é uma característica apenas das vidas de pessoas gays. Mas, para muitas delas, ainda é a característica fundamental da vida social, e há poucas pessoas gays, por mais corajosas e sinceras que sejam de hábito, por mais afortunadas pelo apoio de suas comunidades imediatas, em cujas vidas o armário não seja ainda uma presença formadora (Sedgwick, 2007, p. 22)

Podemos dizer, concordando com Sedgwick, que sair do armário implica negociações e posições de sujeito. Logo, nem sempre a revelação para familiares e pessoas próximas implica uma libertação, pois, a cada revelação, "novos armários são erigidos" (Sedgwick, 2007, p. 22). Logo, sair do armário é também uma negociação política exercida cotidianamente e que, muitas vezes, implica ou pode implicar sofrimento para o sujeito que se revela.

Psicólogos como Anderson (1992), Hardin (2000), Santos (2004) e Castañeda (2007) relatam o sofrimento de jovens que sentem atração e que mantêm relações afetivas e sexuais com pessoas do mesmo sexo quando resolvem assumir sua homossexualidade para si e para os outros.

O percurso de assumir a homossexualidade, em geral, passa por diversos momentos/fases. Primeiramente, no período correspondente à infância e à adolescência, o sentimento de diferença é bastante comum. Ainda que não tenham noção do significado da palavra hetero, homo ou bissexualidade, sentem que não são como os outros, e, invariavelmente, percebem que isso não é bom, o que faz surgir uma sensação de homonegatividade (Baker, 2002, p. 46).

Tal fato predispõe o/a adolescente não heterossexual a negar os seus sentimentos e as suas sensações de atração por pessoas do mesmo sexo ou a se sentir pertencente a outro gênero diferente do socialmente esperado para o seu sexo biológico. Alguns autores, como Castañeda (2007), ressaltam que essa negação pode incapacitar o/a adolescente a desenvolver laços de sociabilidade que lhes serão úteis na vida adulta ou mesmo gerar mecanismos de compensação desnecessários, pois que internalizam uma culpa e/ou 
inferioridade por sentirem o que sentem. Assim, muitos jovens não heterossexuais se sentem na obrigação de agradar os outros por medo de virem a ser rejeitados em função de seus desejos homoeróticos. Tal situação de condenação social da homossexualidade faz com que os/as adolescentes se fechem no armário na tentativa de evitar serem colocados na posição de descrédito ou desacreditados (Goffman, 1982). Nesse caso, a depender do lugar e da frequência com que esses jovens tenham que negociar a abertura ou o fechamento do armário, algo da sensação de integralidade necessária para a formação da identidade se perde, isto é, fica dissociada do sentimento de si mesmo. Por fim, desenvolvem outras estratégias de evitação do estigma - ainda que não consigam sucesso na evitação de seus sentimentos, desejos e atrações homoeróticas — buscando a aceitação social a partir do engajamento em relações amorosas heteroeróticas. Faz parte do senso comum inferir que práticas sexuais com parceiros do mesmo sexo ou de sexo oposto são, por si só, definidoras de uma identidade sexual. Assim, práticas sexuais surgem vinculadas a identidades sexuais, a carreiras sexuais e a estilos de vida (Gagnon, 2006). No entanto, várias pessoas que mantêm práticas sexuais homoeróticas não se assumem como homossexuais (França, 2006). Desse modo, podemos dizer que práticas sexuais não são definidoras de uma identidade sexual.

Um terceiro momento desse processo, que, em muitos casos, não acontecerá na adolescência, mas sim, a partir dos 20 anos, é a aceitação de si mesmo. Tal aceitação coincide com a busca de informações mais claras e positivas sobre a homossexualidade bem como com a tentativa de estabelecimento de relações afetivo-sexuais mais íntimas e menos efêmeras, seguida por tentativas de saída da invisibilidade e do segredo para seus familiares. Segundo Castañeda (2007), esses processos coincidem com aqueles destacados por Kübler-Ross (1969) relativos à elaboração do luto (negação, raiva, barganha mágica, depressão e aceitação), pois que, em sociedades heteronormativas, todas as pessoas são educadas para se tornarem heterossexuais e viverem suas identidades sexuais e de gênero em conformidade com as regras heterossexistas.

Todavia, no que diz respeito à família, Savin-Wiliams (2001, p. 49) destaca que, além de se levar em conta esse "modelo de elaboração do luto" de um filho(a) não heterossexual, outros fatores devem ser considerados na compreensão de como os pais irão reagir à saída do armário de seus/ suas filhos(as). Fatores tais como religião, raça, renda familiar, nível de escolaridade e idade dos pais, o modo como eles descobriram a atração de seus/suas filhos/as pelo mesmo sexo (se lhes foi dito direta ou indiretamente pelo/a filho/a ou por outra pessoa), idade da criança (quanto mais jovem, mais os pais tendem a negar a homossexualidade na criança) e a idade dos pais. Segundo estudos de Modesto (2008) relativos a grupos de pais e mães de pessoas homossexuais empreendidos no Brasil, verificamos que os que mais resistem à elaboração desse luto são os pais cuja religião (católica e/ou evangélica) assume papel preponderante em suas vidas. Todavia, não é possível generalizarmos que o processo de aceitação da homossexualidade de um(a) filho(a) dependa apenas das fases de elaboração de luto. Pesquisas qualitativas realizadas por Savin-Williams (1996, 1998, 2001) demonstram que a existência de uma relação positiva entre pais e filhos(as) anteriormente à questão da homossexualidade ser revelada também são determinantes para bem resolver esse processo de aceitação.

De qualquer modo, parece haver unanimidade entre os resultados de pesquisas relativa ao fato de que a família de origem nesse processo da aceitação de si mesmo, em geral, tem um peso muito importante (Williams, 1998; 
Laird, 1998). Sabemos que as trajetórias percorridas pelos/as adolescentes nessa revelação envolvem contar para o grupo de amigos(as) e/ou para a família. A reação dessas pessoas sobre essa revelação é importante para definir como esses jovens irão traçar seus futuros afetivo-sexuais e construir suas identidades de gênero de modo aceitável e confortável para si mesmos e sem medo de não serem aceitos (Rust, 2003).

Para os pais, as práticas sexuais (homoeróticas) são tidas muitas vezes como passageiras: uma fase. Tal posicionamento da família acaba por ampliar os sentimentos de inadequação desse/a jovem e seu isolamento social. Sendo a adolescência um momento de buscas, de transformações e de tentativas de se encontrar com os iguais, o/a jovem homossexual não encontra outros iguais a ele/a, ou seja, ele/a não encontra no seu grupo de amigos outros jovens que se autodeclarem homossexuais. Nesse caso, já encontramos uma diferença entre as trajetórias de desenvolvimento entre os jovens hetero e homossexuais, pois o discurso heteronormativo favorece, desde tenra idade, o agrupamento de pessoas com a premissa a heterossexualidade, e evita e reprime manifestações que estejam em desacordo com essas normas. Tais práticas e discursos regulatórios atribuem valores negativos às manifestações sexuais e performances de gênero diferentes daquelas esperadas para os padrões heterossexuais (homonegatividade). Logo, o jovem que reconhece em si mesmo a orientação sexual homossexual interpreta a sua diferença como uma anormalidade ou inadequação, o que dificulta a sua integração a um grupo. As brincadeiras na escola, os valores familiares, os valores sociais, amplificados e caricaturados pela mídia produzem discursos sobre a homossexualidade de modo a elegêla como algo indesejável e/ou patológico, assim, seus praticantes são considerados como doentes pela sociedade em geral. Tais valores sociais levam o jovem homossexual ao sofrimento, à dor e, muitas vezes, a tentativas de suicídio (Ramafedi, 1994; Marcus, 1996). Mas seriam esses efeitos iguais para meninos e meninas não heterossexuais? Estariam as jovens lésbicas submetidas aos mesmos fatores que envolvem os já consagrados modelos-desair-do-armário?

Como abordado por Savin-Williams (2001), esses modelos possuem alcances limitados para explicar as trajetórias de desenvolvimento de jovens e suas famílias que saem do armário, isso porque muitos desses estudos não levam em consideração nem as diferenças de gênero (meninas e meninos se relacionam diferentemente com os pais de sexos opostos), nem as configurações familiares (monoparentais, família nuclear, etc), nem os marcadores sociais de diferenças já elencados e tampouco as circunstâncias da vida.

Pautados nas teorias pós-estruturalistas sobre a discussão entre gênero, sexualidade e adolescência, propomo-nos a problematizar as distintas trajetórias afetivo-sexuais entre jovens hetero e não heterossexuais como reguladas pelas práticas e discursos homofóbicos que interferem no processo de saída do armário e em suas relações com as práticas sexuais de risco.

\section{Métodos}

A pesquisa foi realizada em 2009, junto a estudantes do ensino médio em três cidades do oeste paulista (Presidente Prudente, Assis e Ourinhos).

\section{Amostra}

Os resultados aqui apresentados são provenientes de uma amostra formada por 2282 adolescentes de ambos os sexos, sendo: 714 (31.3\%) de Presidente Prudente, 779 (34.1\%) de Assis e 789 (34.6\%) de Ourinhos, regularmente matriculados/as no ensino médio de escolas públicas desses Municípios. 
Trata-se de jovens na sua maioria brancos, 1320 (58.1\%), com idade média de 17 anos (erro padrão $=0.03$ ) e renda familiar de 1 a 5 s.m., $1683(74.7 \%)$.

Para fins de análise, evitando incorrer em erros conceituais, agrupamos os participantes da seguinte maneira: aqueles que se autodefiniram heterossexuais, ou seja, que correspondiam ao sistema sexo/gênero/desejo (Butler, 2003) de acordo com a heteronormatividade (Foster, 2001), foram denominados Grupo A; já aqueles que não tinham correspondência linear com esse sistema, tais como os gays, as lésbicas, os bissexuais, aqueles que se recusaram a se autodefinir ou que responderam "não saber se definir", foram agrupados no Grupo B. Assim, no Grupo A, tivemos 2163 (95.2\%) adolescentes; no Grupo B, estão 12 gays, 11 lésbicas, 39 bissexuais, 9 que se recusaram a se auto-definir, 33 que não sabiam e 5 que deram outras respostas. Dez adolescentes não definiram sua sexualidade.

\section{Instrumento e procedimento da coleta de dados}

O instrumento empregado foi um questionário autoaplicável e adaptado daquele utilizado em pesquisa realizada em 2001 pelo Centre Gai \& Lesbien de Paris em colaboração com pesquisadores do CNRS (Centre National de Recherche Scientifique), sendo que, na versão brasileira, ficou com 131 questões, na sua maioria, fechadas.

Dentre todas as escolas que aceitaram participar do estudo, em cada cidade, fez-se um sorteio aleatório de $50.0 \%$ das classes de primeiro a terceiro ano. Os/as alunos/as pertencentes a essas classes foram esclarecidos/as sobre os objetivos da pesquisa e convidados/as a participar. Aqueles/ as que desejaram contribuir com o trabalho preencheram o questionário de forma anônima, durante o período de uma aula.

\section{Questões éticas}

O projeto foi aprovado junto ao Comitê de Ética em Pesquisa da UNESP (n 547/2007), campus de Assis, e está de acordo com as normas da resolução n 196/96 do CONEP/MS.

\section{Resultados}

A maioria dos/as estudantes se declarou heterossexual, 2159 (95.2\%), sendo 1245 (57.7\%) moças (Tabela 1). Ressaltamos que 4 adolescentes não declararam seu sexo, e 10 não declararam sua orientação sexual.

Tabela 1. Distribuição dos participantes por sexo segundo a sexualidade declarada (Assis, Presidente Prudente, Ourinhos, 2009)

\begin{tabular}{llll}
\hline & \multicolumn{2}{c}{ Sexo } & \\
Orientação sexual & $\begin{array}{c}\text { Masculino } \\
\mathrm{n}(\%)\end{array}$ & $\begin{array}{c}\text { Feminino } \\
\mathrm{n}(\%)\end{array}$ & $\begin{array}{c}\text { Total } \\
\mathrm{n}(\%)\end{array}$ \\
\hline Grupo A & $914(95.4)$ & $1245(95.0)$ & $2159(95.2)$ \\
Grupo B & $44(4.6)$ & $65(5.0)$ & $109(4.8)$ \\
\hline
\end{tabular}

A maioria dos/as respondentes, 2030 (93.2\%), independentemente da orientação sexual, declarou ter sentido atração unicamente por pessoas de sexo biológico diferente. Para aqueles que declararam ter sentido atração unicamente por alguém do mesmo sexo biológico ( $n=23)$, 
independentemente da orientação sexual, essa atração ocorreu em média aos 12 anos (erro padrão $=0.60)$. Nesse contexto, apenas $15(65.2 \%)$, sendo 9 (75.0\%) pertencentes ao Grupo B, disseram ter conversado com alguém sobre o assunto, sendo a amiga, 9 $(60.0 \%)$, a pessoa mais citada.

Com relação aos pertencentes ao Grupo A, a justificativa mais usada para não contar a ninguém foi "achar que fosse passageiro", $13(65.0 \%)$ em 20 respondentes, e, para os do Grupo B, foi "sentir medo de não ser compreendido", 16 (72.7\%) em 22 respondentes, e "ainda não ter certeza sobre os seus sentimentos", 13 (68.4\%) em 19 respondentes.

As razões que mais levaram os jovens do Grupo A a terem tido relação com alguém do sexo biológico oposto foram: "querer perder a virgindade", 208 (96.7\%) em 215 respondentes, "querer agradar o parceiro(a), 159 (97.5\%) em 163 respondentes, e "achar que seria legal", 661 (94.4\%) em 700 respondentes, e, para os do Grupo B, foi "achar que seria legal", 39 (5.6\%) em 700 respondentes. As causas da relação com alguém do mesmo sexo biológico, para o Grupo B, foram para "sentir como seria, para experimentar", 17 respondentes, "achar que seria legal", 10 respondentes, e/ou "gostar da pessoa", 13 respondentes.

Observamos que 24 jovens pertencentes ao Grupo B já disseram ter tido relação sexual com pessoas de ambos os sexos, sendo que, dentre eles, encontramos 13 bissexuais, 1 gay, 5 lésbicas e 5 outras. Porém, em apenas 13 casos (sendo 10 do sexo feminino) houve penetração, e, dentre esses, 10 usaram o preservativo com a pessoa de sexo biológico diferente.

É importante informar que nenhum dos adolescentes, independentemente da orientação sexual, que disseram ter tido relação sexual unicamente com alguém de sexo biológico igual, responderam se houve ou não penetração na primeira relação sexual bem como se usaram ou não o preservativo. Entre os adolescentes que disseram ter tido relação sexual unicamente com alguém de sexo biológico oposto, apenas 19 (2.4\%) do Grupo B (sendo 15 do sexo feminino) declararam ter havido penetração, e 18 $(2.3 \%)$ ter usado o preservativo, enquanto 774 (97.6\%) do Grupo A fizeram essa afirmação, e 767 (97.7\%) declararam usar o preservativo. Nesse contexto, para ambos os sexos, a maior preocupação foi a de evitar a gravidez e as DSTs/HIV/AIDS, 266 (40.9\%) rapazes e 384 (59.1\%) moças. Contudo, os rapazes estão mais preocupados em evitar as DSTs/HIV/AIDS, 13 (59.1\%), e as meninas, em evitar a gravidez, 53 (53.0\%).

Dentre 18 pessoas (do Grupo B) que tiveram relação com alguém do mesmo sexo, a maioria, $13(72.2 \%)$, disse ter tido de 1 a 5 parceiros. O mesmo ocorreu para aqueles que disseram ter tido relação sexual com ambos os sexos, sendo que, em 22 do Grupo B, 18 (81.8\%) declararam terem tido de 1 a 5 parceiros. Todavia, esse número cai quando falamos de parceiros de sexo biológico oposto; a maioria, tanto do Grupo A quanto do Grupo B, tem de 1 a 3 parceiros. Vale ressaltar que praticamente apenas os heterossexuais, 47 (5.1\%), declararam ter tido mais de 11 parceiros. Do mesmo modo, apenas os jovens do Grupo B apresentaram frequências de 4 ou mais parceiros nas relações com ambos os sexos.

Observamos que, em 771 (33.8\% da amostra) adolescentes que declararam estar namorando no período da pesquisa, 6 (0.8\%) do Grupo A disseram ser com alguém de mesmo sexo biológico, ao passo que 18 (54.5\%) do Grupo B estavam com alguém de sexo biológico diferente.

Nenhum dos estudantes disse ter mais de um namorado(a) do mesmo sexo que o seu, 
porém $8(1.1 \%)$ heterossexuais disseram ter mais de um namorado(a) do sexo biológico oposto, e desses, 5 responderam que já tiveram relação sexual, sendo que 3 disseram usar o preservativo.

O tempo de namoro mais frequente na amostra foi de 0 a 3 meses, tanto para o Grupo A, 218 (29.9\%), quanto para o Grupo B, 13 (39.4\%). Para o Grupo A, quando comparamos o sexo dos adolescentes, 86 (40.4\%) meninos encontram-se nessa faixa de tempo de namoro, porém, para as meninas, existe maior variação, isto é, 132 (25.6\%) estão na faixa de 0 a 3 meses de namoro, e 150 (29.1\%), na faixa igual ou superior a 18 meses.

Em um total de 100 adolescentes do Grupo B, 54 disseram ter assumido sua sexualidade para alguém, sendo que, nessa categoria geral, os que mais se assumiram foram os bissexuais 19 (35.2\%), os gays, 11 (20.4\%), e os que se declararam outros 15 (27.8\%). Todavia, quando analisados por subcategorias, temos que, para os bissexuais, 19 (52.8\%) já se assumiram, seguidos por $11(91.7 \%)$ gays, 9 (81.8\%) lésbicas e 15 (36.6\%) outros. Vê-se, portanto, que os inseridos nas categorias outros e bissexuais são, proporcionalmente, os menos assumidos na amostra por subcategoria. Vale dizer que as perdas de respondentes a essa questão, além de baixas, se concentraram entre os bissexuais e os outros.

Com relação para quem a sexualidade foi assumida, o(a)s amigo(a)s próximo(a)s são as pessoas mais citadas em todos os grupos, seguidos pelos colegas de escola e pela mãe. Quando perguntados sobre como vivem sua sexualidade, as perdas de respondentes foram mais expressivas (39 em 109). Todavia, quando verificamos os respondentes em cada subcategoria do Grupo B, entre $60.0 \%$ a $70.0 \%$ responderam essas questões. Encontramos dados muito interessantes no que diz respeito ao modo como vivenciam a sua sexualidade. Para 29 (41.4\%) do total de 70 respondentes que disseram viver muito bem a sua sexualidade e se sentirem aceitos por todas as pessoas que lhes são importantes, 16 (55.2\%) já se assumiram. Dentre estes, a categoria outros é a menos assumida. Nesse contexto, os 4 (25.0\%) gays que responderam essa questão formam também a única categoria em que todos já se assumiram e vivem muito bem a sua sexualidade.

Quando indagados se se sentem bem, isto é, se são aceitos pela maioria (não todas) das pessoas que importam para eles, apenas 12 (17.1\%) assinalam essa alternativa, sendo que, nesse caso, o grupo dos que não assumiram cai para $3(25.0 \%)$.

Apenas um bissexual disse ter se assumido, e que algumas pessoas importantes para ele/ela não o/a aceitam. O total de pessoas que não assumiu foi de 39 (55.7\%) em 70 respondentes. Dentre elas, $5(12.8 \%)$ ainda não contaram, mas irão fazê-lo, 6 (15.4\%) jamais irão contar, 10 (25.6\%) procuram não pensar sobre sua sexualidade, e 2 (5.1\%) estão tentando mudá-la.

Observamos que, nesses casos, com exceção de uma respondente lésbica, todos os respondentes pertencem ao agrupamento de bissexuais, gays e outros.

Por fim, dentre os 38 bissexuais da amostra, $33(87.0 \%)$ responderam a questão sobre já terem sofrido algum constrangimento/ agressão por causa da sua sexualidade. Dentre estes, 18 (54.5\%) afirmaram que sim. Para o agrupamento outros, as agressões foram menos frequentes, pois apenas 9 (30.0\%), em 30 respondentes desse agrupamento, disseram já terem sido vítimas de agressões. Todos os gays e lésbicas da amostra responderam essa questão e, no seu caso, praticamente $80.0 \%$ já sofreu agressões, e são eles, dentre todos os agrupamentos do 
Grupo B, os mais assumidos. Contudo, 32.6\% dos 86 jovens vítimas de agressões, apenas 8 (28.6\%) declararam que gostariam de mudar de sexualidade, se isso fosse possível.

\section{Discussão dos resultados}

Os resultados mostram que não apenas é possível mas também comum que os/as adolescentes se sintam atraídos/as pelos dois sexos e com eles tenham práticas sexuais. Mas isso parece ser um fato muito mais comum naqueles casos em que o adolescente se declarou bissexual, lésbica ou outro. Ademais, foram pouquíssimos os casos de adolescentes que se definiram heterossexuais e que tiveram relações homoeróticas; assim, embora possível para os integrantes do Grupo B, o inverso não é tão provável. Perguntamo-nos: a que se deve essa lógica? Estariam os/as adolescentes que têm atrações e desejos exclusivamente por pessoas de mesmo sexo biológico ou por ambos se sentindo pressionados a experimentar o sexo com pessoas de sexo biológico diferente do seu? Se sim, o que os/as pressiona? Eles/ as próprios/as? A sociedade? Observamos que, com exceção dos/as jovens que são mais assumidos/as, isto é, as lésbicas e os gays (para os quais a prevalência de prática sexual com pessoas de sexo biológico diferente foi menor), foram muitos os casos de adolescentes autodeclarados/as bissexuais ou na categoria outros que não aceitam sentirem-se atraídos por pessoas do mesmo sexo biológico, que têm medo de serem rejeitados por pessoas que importam para eles/as, e apenas nesses casos revelou-se o desejo de mudar a orientação sexual, caso isso fosse possível.

O fato de não encontrarmos pessoas do Grupo A experimentando o prazer no sexo com pessoas de mesmo sexo biológico na mesma proporção que as pessoas do agrupamento $B$ não significa que as primeiras estejam satisfeitas com sua sexualidade, senão que a heterossexualidade é mais aceita, pois aqueles que não correspondem à prerrogativa heteronormativa na nossa amostra deixam claro o preço que pagam por se comportarem de modo diferente da maioria, pois são agredidos/as, sentem medo de serem rejeitados/as pelas pessoas que importam para eles/elas, vivem na maior parte dos casos na invisibilidade e ainda têm de se preocupar com as modulações de abertura e de fechamento do armário, fato que não preocupa nem um pouco as pessoas heterossexuais que seguem suas vidas com a permissão e o direito de serem o que são em todos os espaços sociais em que circulam.

Em uma sociedade homofóbica, o/a adolescente pode muitas vezes se declarar heterossexual, mas manter relações afetivo/ sexuais às escondidas com adolescentes do mesmo sexo biológico. Isso pode ter duas explicações: de um lado, podemos entender que a produção discursiva da homofobia pode gerar o que chamamos de discursos de resistência, um contra-poder, como apontado por Foucault (1981). Em outras palavras, há uma autodeclaração de heterossexualidade, mas o desejo, e mesmo as práticas sexuais, se dirigem às pessoas de mesmo sexo biológico. Entretanto, isso pode ser apenas uma estratégia de sobrevivência, como nos casos em se houve uma piada de mau gosto mas, para não arrumar confusão, disfarça-se, finge-se que tudo vai bem e segue-se na invisibilidade. De outro modo, lembremos que os/as respondentes ainda são jovens e, por isso, não se sentem obrigados/ as a dar satisfações para ninguém. Podem continuar fingindo que não sentem desejos homoeróticos sem se sentirem em dívida com qualquer pessoa. É um pouco o que 
explica também o fato de que cerca de $50 \%$ dos casos de respondentes do Grupo B que disseram se sentir muito bem com sua sexualidade ainda serem pessoas que não assumiram uma identidade sexual. Até que encontrem o amor, que se sintam aprisionados ao doce e angustiante temor de perder a quem se ama, bem como o conflito de fidelidade ao sentimento à pessoa amada ou à invisibilidade do desejo se instaure, é possível que sigam se sentindo muito bem. No entanto, há sempre um preço (e alto) em se manter no armário, mas, ao que parece, ainda não é suficiente para permitir aos/às jovens bissexuais de nossa amostra saírem do armário. Todavia, não podemos generalizar também aqui, pois uma pesquisa qualitativa que pudesse conhecer esses/as jovens se faria necessária, já que não podemos avaliar se o fato de sair do armário, no caso dos gays e das lésbicas da amostra, foi uma opção ou simplesmente porque não conseguiam esconder seus sentimentos e gestos, e foram aprisionados/as nos armários dos estereótipos, o que justificaria também as agressões sofridas.

Outro aspecto importante e que precisamos levar em consideração é que as práticas sexuais não são necessariamente geradoras de identidades sexuais. Há que se levar em conta também as produções discursivas das identidades (Foucault, 1982/1994; Silva, 2007), logo, não são parte da essência do sujeito. Desse modo, pode-se pensar que sejam transitórias e aliadas a estilos de vida e de comportamento. Nesse sentido é que podemos também pensar em trajetórias sexuais que oscilam mais do que em rotas pré-determinadas. Isso é demonstrado neste estudo, pois um grande número de jovens do Grupo B já se sentiram atraídos/as e já mantiveram relações sexuais com pessoas do mesmo sexo biológico ou do sexo biológico oposto.
Outro dado que merece destaque é quando esses jovens conversam com alguém sobre tal atração por pessoas de mesmo sexo biológico, isto é, aqueles que se declaram heterossexuais, mas que sentem atração por pessoas de mesmo sexo biológico não conversam com alguém sobre isso, pois sentem medo: medo de rejeição, medo de incompreensão e de intolerância por parte de amigos ou de familiares. Ao que tudo indica, correm o risco de viver seus medos no silêncio, não buscando experiências afetivas duradouras, e isolam-se.

Eribon, em seu esforço de mostrar como os gays são sujeitados pela heteronormatividade e, ao mesmo tempo, como resistem a ela em diferentes momentos históricos, produzindo uma cultura gay, apresenta-nos um quadro doloroso dessa questão:

\footnotetext{
"O indivíduo gay é fadado ao isolamento, ao individualismo, seja na vergonha (o desprezo para consigo mesmo como gay) seja no orgulho (o desprezo elitista para com os outros gays). Mas, por ser produzido pelos mesmos processos de 'sujeição' (...), ele necessariamente pertence, e contra a sua vontade, a esse 'coletivo' que ele recusa" (2008, p. 159)
}

Nesse sentido, cabe aqui pontuar sobre quais seriam as consequências desse tipo de isolamento ao longo da vida como matéria para pesquisas futuras.

Um lugar comum e que muitas vezes reforça os discursos homofóbicos é a crença no fato de que, se os homossexuais pudessem escolher sua sexualidade, eles escolheriam a heterossexualidade. Tal narrativa discursiva tem base no heterocentrismo que justifica muitos discursos religiosos vigentes, ou seja, trata-se de uma hipervaloração da heterossexualidade em relação a qualquer outra forma de orientação sexual. Ademais, 
reforça a falsa ideia de que a homossexualidade seria sinônimo de uma vida sofrida, difícil, perversa e inútil em si e por si mesma. Mas esse estudo também desconstrói esse discurso homofóbico, pois os pertencentes ao Grupo $B$, quando inquiridos sobre a possibilidade de escolher outra sexualidade que não a homossexual, optaram por continuar como são, ainda que já tenham sido vitimizados por agressões e constrangimentos. Isso nos mostra claramente que uma identidade não heteronormativa não produz em si mesma o sofrimento ou a exclusão. Se estes existem, e para alguns é fato, é por efeito da homofobia. E talvez seja essa a explicação possível para o fato de que aqueles que demonstraram maiores (e em alguns casos as únicas) prevalências de sofrimentos recaiam sobre os autodeclarados bissexuais ou os do agrupamento outros.

A pesquisa também mostra que os respondentes do agrupamento $B$ parecem usar o preservativo quando se relacionam sexualmente com pessoas de sexo oposto, porém, não nos foi possível saber se o mesmo procedimento é tomado quando têm relações sexuais com pessoas de mesmo sexo biológico, já que não houve respostas.

Por fim, o número de parcerias sexuais para além de 3, proporcionalmente, ainda reside no agrupamento $B$, bem como é nesse agrupamento que encontramos maiores frequências de relações sexuais dos 6 aos 10. De modo algum se pode inferir daí uma suposta promiscuidade instaurada na condição homossexual ou na daqueles que ainda não se assumiram em alguma subcategoria. Outrossim, podemos afirmar que, em uma sociedade homofóbica, o jovem que não se identifica com os padrões heteronormativos terá maiores dificuldades de exercitar os rituais de enamoramento e paixão, comuns aos jovens que vivem de acordo com a heteronormatividade. Assim, não terão chances de se beijarem em espaços públicos, de se abraçarem, etc, como sabemos ser possível para os jovens que se dizem heterossexuais. Logo, diante da mais remota oportunidade surgida para o jovem que não segue os padrões heteronormativos de vir a ter um contato afetivo/sexual com alguém de mesmo sexo biológico, ele/a irá agarrá-la. Não podemos nos esquecer também de que somos educados para sermos heterossexuais. Assim, o jovem não heterossexual é, como os heterossexuais, educado para ser heterossexual, reproduzindo, portanto, as normativas machistas e sexistas comuns a essa orientação sexual. Logo, os jovens gays, bissexuais ou os da categoria outro do sexo masculino de nossa amostra irão, tal qual os adolescentes heterossexuais do sexo masculino, se sentir autorizados, mais do que as meninas, a ter muitos parceiros. Vemos aí um problema muito mais ligado à questão da educação dos gêneros do que propriamente a um fato da homo ou da bissexualidade.

\section{Conclusão}

Como disse Savin-Williams (2005), existem variados e amplos fatores que afetam as trajetórias sexuais de jovens não heterossexuais: eventos pessoais, histórias de vida, vínculos familiares e de amizade. Isso se evidenciou de forma contundente nesta pesquisa, que revelou inclusive jovens que se autodeclaram heterossexuais e que mantêm ou já mantiveram relações sexuais com jovens do mesmo sexo biológico.

Não deixa de ser importante ressaltar também a pouca preocupação com o uso do preservativo em suas relações sexuais e o grande número de jovens que já sofreram alguma violência entre os pertencentes ao Grupo B. Sendo a nossa sociedade fundada 
em bases heteronormativas, as diversas formas de expressão do desejo sexual perdem sua inteligibilidade, já que não correspondem à simplista fórmula binária naturalizada de que o gênero se define, tanto quanto o desejo, pelo sexo biológico. Mas, como mostra Butler (2003, 2005), é a partir dos discursos das margens, ou seja, do que é considerado abjeto socialmente, que a heteronormatividade é confrontada. Desse modo, mesmo em uma sociedade francamente homofóbica, jovens gays, lésbicas e bissexuais encontram formas de expressão de sua sexualidade e questionam o futuro da inteligibilidade das normas e dos valores heteronormativizados, isto é, não mais um discurso que questione a precedência ou mesmo a importância das identidades sexuais e de gêneros, mas antes, a relevância desta ou daquela norma em relação às práticas sexuais e às expressões desejantes.

Financiamento: Trata-se de projeto de pesquisa aprovado em Edital lançado em 2007 financiado e apoiado pelo Programa Nacional de DST-HIV/AIDS (Ministério da Saúde do Brasil) em parceria com a UNODC (Escritório das Nações Unidas contra Drogas e Crimes) e a Secretaria Especial dos Direitos Humanos do Ministério da Justiça do Brasil identificado sobre o número 251/07. Tal projeto foi desenvolvido em regime de parceria pelas seguintes instituições: ONG NEPS (Núcleo de Estudos e Pesquisas sobre as Sexualidades), na qualidade de mantenedora, pelo Grupo de Estudos e Pesquisas sobre as Sexualidades (GEPS) vinculado ao Departamento de Psicologia Clínica da UNESP de Assis. AGRADECIMENTOS: O projeto recebeu sugestões de leitura e apoio na sua execução, de alunos/as e pesquisadores/as, a saber: Prof. Dr. Pedro Henrique Godinho e Profa. Dra. Maria Laura Nogueira Pires (UNESP, Assis, Departamento de Psicologia Experimental e do Trabalho), Profa. Dra. Arilda Inês Miranda Ribeiro (UNESP-Presidente Prudente via NUDISE [Núcleo de Diversidade na Educação]), Prof. Dr. Fernando Seffner (UFRGS), Profa. Dra. Stella Regina Taquette (UERJ), Elcio Nogueira dos Santos, MS (PUC/SP), Luis Ramires Neto, MS (C.O.R.S.A) e Profa. Dra. Regina Fachinni (UNICAMP), Moisés Alessandro de Souza Lopes (Doutorando em Antropologia da UnB), Maytê Gouvea Coleto (Mestranda em Educação na UNESP de Presidente Prudente). 


\section{Fernando Silva Teixeira-Filho}

Mestre e Doutor em Psicologia Clínica pela Pontifícia Universidade Católica de São Paulo. Atualmente é professor assistente doutor (nível II) na Universidade Estadual Paulista, São Paulo- SP - Brasil.

Líder do Grupo de Estudos e Pesquisas sobre as Sexualidades (GEPS)

E-mail: fteixeira@assis.unesp.br

\section{Carina Alexandra Rondini}

Matemática, Profa. Assistente Doutora junto ao Departamento de Psicologia Experimental e do Trabalho da Universidade Estadual Paulista, Campus de Assis, SP.

Membro do Grupo de Estudos e Pesquisas sobre as Sexualidades (GEPS)

E-mail: carondini@yahoo.com.bre/ou carina@assis.unesp.br

\section{Elcio Nogueira dos Santos}

Psicólogo, Doutorando em Psicologia Social pela Pontifícia Universidade Católica de São Paulo

Membro do Grupo de Estudos e Pesquisas sobre as Sexualidades (GEPS)

E-mail: elcionsantos@uol.com.br

\section{Andressa Benini Mendes}

Psicóloga formada pela Universidade Estadual Paulista, Campus de Assis, SP

Membro do Grupo de Estudos e Pesquisas sobre as Sexualidades (GEPS)

E-mail: andressa.benini@gmail.com

\section{Endereço para envio de correspondência:}

Departamento de Psicologia Clínica da Universidade de São Paulo

Av. Dom Antônio, 2100, Assis, São Paulo - SP. CEP: 19806.900 


\section{Referências}

Anderson, D. (1992). Homossexualidade na adolescência (A. M. M. Singule, trad.). In Sugar, M. (Org.), Adolescência atípica e sexualidade (pp.160-176). Porto Alegre: Artes Médicas.

Ariès, P. (1978). História social da criança e da família (D Flaksman, trad.). Rio de Janeiro: LTC (Trabalho original publicado em 1973).

Bailley, J. M., \& Pillard, R. C. (1991). A genetic study of male sexual orientation. Archives of general psychiatry, 48(12), 1089-1096.

Baker, J. M. (2002). How homophobia hurts children. Nurturing diversity at home, at school, and in the community. New York: Harrington Park Press.

Badinter, E. (1985). Um amor conquistado. O mito do amor materno. Rio de Janeiro: Nova Fronteira.

Beauvoir, S. (1980). O segundo sexo. Rio de Janeiro: Nova Fronteira. (Trabalho original publicado em [1949])

Borrillo, D. (2001). Homofobia. Barcelona: Bellaterra.

Butler, J. (2003). Problemas de gênero. Feminismo e subversão da identidade (R. Aguiar, trad). Rio de Janeiro: Civilização Brasileira.

Butler, J. (2005). Cuerpos que importan - sobre los limites materiales y discursivos del "sexo". Buenos Aires, Barcelona: Paidós.

Butler, J. (1987). Variações sobre sexo e gênero. Beauvoir, Wittig e Foucault. In S. Benhabib, \& D. Cornell. Feminismo como crítica da modernidade. Rio de Janeiro: Ed. Rosa dos Tempos.
Carrara, S., Ramos, S., Simões, J. A., \& Facchini, R. (Orgs.), (2006) Políticas, direitos, violência e homossexualidade - pesquisa 9a Parada do Orgulho GLBT de São Paulo - 2005. Rio de Janeiro: CEPESC.

Castañeda, M. (2007). A experiência homossexual: explicações e conselhos para os homossexuais, suas famílias e seus terapeutas. São Paulo: A Girafa Editora.

Costa, J. F. (1992). A inocência e o vício: estudos sobre o homoerotismo. Rio de Janeiro: Relume-Dumará.

Costa, J. F. (1995). A face e o verso: estudos sobre o homoerotismo II. São Paulo: Escuta.

Currier, R. L. (1985). Perspectiva global da sexualidade dos jovens. In L.L. Constantine, \& F. M. Martinson. Sexualidade infantil: novos conceitos, novas perspectivas (pp. 8-17). São Paulo: Livraria Roca

Eribon, D. (2008). Reflexões sobre a questão gay. Rio de Janeiro: Companhia de Freud.

Facchini, R., França, I. L., \& Venturi, G. (Orgs.), (2007). Sexualidade, cidadania e homofobia: pesquisa $10^{a}$ Parada do Orgulho GLBT de São Paulo - 2006. São Paulo: APOGLBT.

Foucault, M. (1981). Microfísica do poder. Rio de Janeiro: Edições Graal.

Foucault, Michel. (1982). Michel Foucault, uma entrevista: sexo poder e política da identidade. (Entrevista originalmente publicada como "Michel Foucault, une interview: Sexe, pouvoir et la politique de la identité"). The advocate, $\mathrm{n}^{\circ}$ 400, 7 de agosto de 1984, pp. 26-30 ("Michel Foucault, an interview: Sex, power and the politics of identity"; entrevista 
com B. Gallagher e A. Wilson, Toronto, 22 de junho de 1982; F. Durant-Bogaert, trad.).

França, I. L. (2006). Cercas e pontes - o movimento GLBT e o mercado GLS na cidade de São Paulo. Dissertação de mestrado, Programa de Pós-Graduação em Antropologia, Universidade de São Paulo, São Paulo.

Freud, S. (1981). Tres ensayos para una teoria sexual. In Edição Obras Completas de Sigmund Freud. (Tomo II, 4a ed.). Madri: Ed. Biblioteca Nueva. (Trabalho original publicado em 1905)

Gagnon, J. H. (2006). Uma interpretação do desejo. Ensaios sobre o estudo da sexualidade. Rio de Janeiro: Garamond.

Goffman, E. (1982). Estigma: notas sobre a manipulação da identidade deteriorada (4a ed.). Rio de Janeiro: Zahar.

Hall, S. (1981). Notes on deconstructing the popular. In People's history and socialist theory. London: Routledge.

Hall, S. (2000). Quem precisa de identidade? In T. T. Silva. (Org.), Identidade e diferença - a perspectiva dos estudos culturais (pp.103-131). Petrópolis, RJ: Vozes.

Hamer, D., Hu, S., Manguson, V. L., Hu, N., \& Pattattucci, A. M. L. (1993). A linkage between DNA markers on the $X$ chromosome and male sexual orientation. Science, 161, 321-327.

Hardin, K. N. (2000). Auto-estima para homossexuais: um guia para o amor próprio. São Paulo: GLS/SUMMUS.

Kristeva, J. (1982). Powers of horror. An essay in abjection (Roudiez, L., trad.). New York: Columbai University Press.

Kübler-Ross, E. (1969). On death and dying. New York: Macmillan.

Laird, J. (1998). Invisible ties: Lesbians and their families of origin. In C. J. Patterson, \& A. R. D'Augelli, Lesbian, gay, and bisexual identities in families. Psychological perspectives (pp.197-228). New York: Oxford University Press.

LeVay, S. (1991). A difference in hypothalamic structure between heterosexual and homosexual men. Science, 253, 1034-1037.

Marcus, E. (1996). Why suicide? Answers to 200 of the most frequently asked questions about suicide, attepted suicide, and assisted suicide. San Francisco: Harper San Francisco.

Martinson, M. F. (1984). Sexualidade na pré-adolescência: latente ou manifesta? In L. L. Constantine, \& F. M. Martinson. Sexualidade infantil: novos conceitos, novas perspectivas (pp.75-83). São Paulo: Livraria Roca .

Modesto, E. (2008). Mãe sempre sabe? Mitos e verdades sobre pais e seus filhos homossexuais. São Paulo: Record.

Mott, L. (2000). Assassinato de homossexuais. Manual de coleta de informações, sistematização \& mobilização política contra crimes homofóbicos. Salvador: Editora Grupo Gay da Bahia.

Oliveira, V. M. (2007). Identidades interseccionadas e militâncias políticas. In M. Grossi, A. P. Uziel, \& L. Melo, Conjugalidades, parentalidades e identidades lésbicas, gays e travestis. Rio de Janeiro: Garamond.

Remafedi, G. (Ed). (1994). Death by denial. Studies of suicide in gay and lesbian teenagers. Boston: Alyson Publications, Inc.

Rios, R. R. (2002). O princípio da igualdade e a discriminação por orientação sexual: a homossexualidade no direito brasileiro e norte-americano. São Paulo: Revista dos Tribunais.

Rubin, G. (1975). The traffic in women. Notes on the "political economy" of sex. In R. Reiter, (Ed.). Toward an anthropology of women. New York: Monthly Review Press.

Rubin, G. (1984). Thinking sex: Notes for a radical theory of the politics of sexuality. In H. Abelove, M. Barale, \& D.
Halperin, (Eds.), The lesbian and gay studies reader. Nova York: Routledge. ( Trabalho original publicado em 1984).

Rust, P. C. (2003). Finding a sexual identity and community: Therapeutic implications and cultural assumptions in scientific models of coming out. In L. D. Garnets, \& D. C. Kimmel, (Eds.), Psychological perspectives on lesbian, gay, and bisexual experiences (pp.227-269). New York: Columbia Univesity Press.

Rubin, G. (1993). Thinking sex: Notes for a radical theory of the politics of sexuality. In H. Abelove, M. Barale, \& D. Halperin, (Eds.)

The lesbian and gay studies reader. Nova York: Routledge. (Trabalho original publicado em 1984).

Ryan, C., \& Futterman, D. (1998). Lesbian \& gay youth. Care \& counseling. The first comprehensive guide to health \& mental health care. New York: Columbia University Press.

Santos, B. R. dos. (1996). A emergência da concepção moderna de infância e adolescência -mapeamento, documentação e reflexão sobre as principais teorias. Dissertação de mestrado, Programa de Estudos Pós-Graduados em Ciências Sociais, Pontifícia Universidade Católica de São Paulo, São Paulo

Santos, E. N. dos. (2004). Conto ou não conto? Os sentidos e os significados de tornar pública a orientação sexual homossexual para adolescentes masculinos da cidade de São Paulo. Dissertação de mestrado, Programa de Estudos Pós-Graduados em Psicologia Social, Pontifícia Universidade Católica de São Paulo, São Paulo

Savin-Williams, R. (1990). Gay and lesbian youth: expressions of identity. New York: Hemisphere Publishing Corporation.

Savin-Williams, R., \& Cohen, K. (1996). The lives of lesbians, gays and bisexuals: Children to adults. Fort Worth: Harcourt Brace.

Savin-Williams, R. (1998). "... And then I became gay": Young men's stories. New York: Routledge.

Savin-Williams, R. (2001). Mom, dad. I'm gay. How families negotiate coming out. Washington, DC: American Psychological Association.

Savin-Williams, R. (2005). The new gay teenager. Cambridge: Harvard University Press.

Scott, J. (1989, December). Gender: Useful category of historical analysis. American Historical Review, 91.

Sedgwick, E. K. (2007). A epistemologia do armário (P. Dentzien, trad., S. Miskolci \& J. A. Simões, rev.). Cadernos Pagu, 28, 19-54.

Seidman, S. (2003). The social construction of sexuality. New York: W. W. Norton \& Company.

Silva, T. T. (Org.). (2007). Identidade e diferença: a perspective dos estudos culturais (7a ed.). São Paulo:Vozes.

WHO (World Health Organization). (1986). Young people's health - A challenge for society. Report of a WHO Study Group on Young People and "Health for All by the Year 2000". Genebra, WHO (World Health Organization Technical Report Series, 731).

Williams, W. L. (1998). Social acceptance of same relationships in families: Models from other cultures. In C. J. Patterson, \& A. R. D'Aaugelli, Lesbian, gay, and bisexual identities in families. Psychological perspectives (pp. 53-71). New York: Oxford University Press.

Weeks, J. (1985). Sexuality and its discontents: Meanings, myths and modern sexualities. London: Routledge and Kegan Paul. 